\title{
Laparoscopy versus open surgery for adnexal masses in pregnancy: a meta-analytic review
}

\author{
Piaopiao $\mathrm{Ye}^{1} \cdot \mathrm{Na} \mathrm{Zhao}^{1} \cdot$ Jing Shu ${ }^{2} \cdot$ Heping Shen ${ }^{2} \cdot$ Yanpeng Wang $^{2} \cdot$ Lifeng Chen $^{2} \cdot$ Xiaojian Yan $^{1}$ (I)
}

Received: 16 October 2018 / Accepted: 22 December 2018 / Published online: 31 January 2019

(c) The Author(s) 2019, corrected publication 2019

\begin{abstract}
Purpose The objective of this meta-analysis is to investigate and compare the pregnancy outcomes of laparoscopy and open surgery in the treatment of ovarian tumors during pregnancy.

Methods Search was conducted using MEDLINE, EMBASE, and Cochrane Databases from January 1990 to November 2018. A broad search strategy was used to identify studies comparing laparoscopy and open surgery in pregnancy. Inclusion criteria included comparative studies with the quantitative outcome data on gravida. Two authors independently reviewed and assessed for the quality of included studies according to the Newcastle-Ottawa Scale. Data were extracted for fetal loss, preterm delivery, duration of surgery, blood loss and length of hospital stay.

Results Nine retrospective trials were identified involving 985 patients. No statistical significance was found in fetal loss between laparoscopy and open surgery $(P$ value $=0.334)$. The pooled estimate for preterm labor statistically significantly decreased for laparoscopy group $(P$ value $=0.014)$. Reduced operative blood loss was found in laparoscopy group by $83.81 \mathrm{ml}$ $(P$ value $=0.015)$. Duration of operation may be longer in the laparoscopy group, but without statistical significance $(P$ value $=0.346)$. Length of hospital stay was shorter in the laparoscopy group with reduction of 1.95 days $(P$ value $<0.001)$. Conclusions The available low-grade evidence suggests that laparoscopic surgery might be a feasible alternative for pregnant women with adnexal masses.
\end{abstract}

Keywords Laparoscopy $\cdot$ Open surgery $\cdot$ Adnexal masses $\cdot$ Pregnancy $\cdot$ Meta-analysis

\section{Introduction}

The incidence of adnexal mass in pregnancy is about 41 in 1500 pregnancies [1]. These tumors are mostly benign, corpus luteum cyst is the most common type, it will disappear in $90 \%$ cases by the second trimester of pregnancy, followed by serous cystadenoma and dermoid cyst, which is the most common pathologies found [2-5]. Only approximately 1 in 25,000 pregnancies were observed to be malignant ovarian tumors [6]. Surgery is deemed to be dangerous for both the mother and the fetus, especially in emergency situations

Piaopiao Ye and Na Zhao: Joint first authors.

Xiaojian Yan

yxjbetter2016@hotmail.com

1 Department of Gynecology, The First Affiliated Hospital of Wenzhou Medical University, Wenzhou 325000, China

2 Department of Gynecology, Zhejiang Provincial People's Hospital, Hangzhou 310014, China
$[2,7,8]$, which may lead to a high incidence of maternal complications, fetal death and premature birth [9]. However, for pregnant women with acute pelvic pain or an adnexal mass greater than $6 \mathrm{~cm}$ in diameter, selective surgical excision is not disputed. As the pregnancy progresses, they may occur in torsion, rupture, or leakage of the cyst, which may cause damage to both the mother and the fetus $[2,10]$. In all, ovarian tumors in pregnancy requiring surgical intervention vary from 0.0004 to $0.36 \%[11,12]$. The procedures include resection of the tumor, oophorectomy, or salpingo-oophorectomy and so on. And the best surgical approach for a pregnancy with adnexal masses remains controversial. Since the mid-1990s, laparoscopy has been widely used in nonpregnant women's gynecologic diseases. Nowadays, a growing number of evidence shows that laparoscopy can be safely and effectively used during pregnancy, and provides several advantages, including reduced postoperative pain, analgesic use and hospitalization time [13-19]. At the same time, some surgeons have been hesitant to perform minimally invasive surgery on pregnant patients. Potential concerns 
associated with pregnancy laparoscopic surgery include limited surgical manipulations, perforation of gravid uterus and hypercarbia [20, 21]. Laparoscopic surgery for a pregnancy with adnexal mass has been limited to case reports and retrospective studies in the last decade [9, 22-25]. No prospective controlled studies have been reported yet. Therefore, a meta-analysis was conducted.

The main purpose was to investigate and compare the pregnancy outcomes of two methods in the treatment of ovarian tumors during pregnancy, including fetal loss rate, premature delivery rate, operative time, bleeding volume and hospital stay.

\section{Methods}

\section{Search strategy and eligibility criteria}

A literature search was performed by searching MEDLINE, EMBASE, and Cochrane Databases to obtain comparative studies assessing the safety and efficiency between laparoscopy and laparotomy in women undergoing surgery for adnexal mass during pregnancy. The following mesh search headings were used: ("laparoscopic" or "laparoscopy") and ("abdominal" or "laparotomy") and ("pregnancy" or "pregnant" or "gravida") and ("comparative studies and adnexal mass, and surgery"). Searches were also performed under the terms "laparoscopic versus open" and "minimally invasive versus conventional". There was no restriction by language, or "publication status applied". The "related articles" function was used to broaden the search, and all abstracts, studies, and citations scanned were reviewed. The latest date for this search was November 30, 2018.

\section{Inclusion criteria}

To enter our analysis, studies had the following criteria:

(1) It was a comparative study between LA and OP with the quantitative outcome data on gravida.

(2) Report on at least one of the outcome measures mentioned below.

(3) If the same institution and/or authors reported more than one study, we enrolled the larger scale number studies or higher quality studies.

(4) Study was published in English.

\section{Exclusion criteria}

The following criteria were used to exclude studies from our analysis:
(1) Studies in which the outcomes of interest (mentioned below) were not reported for the two techniques or it was impossible to extract these from the published results.

(2) Studies that used variations on the standard laparoscopic technique, including hybrid procedures (laparoscope-assisted) and single trocar techniques.

(3) There was considerable overlap between authors, centers, or patient cohorts evaluated in the published literature.

\section{Data extraction}

Two reviewers independently extracted the following data from each study: first author, year of publication, study design, mean age, intraoperative data (operative time, blood loss) and postoperative data (hospital stay) and outcomes (pregnancy outcome). Inconsistencies between reviewers' data were resolved through discussion until a consensus was reached. The quality of included studies was estimated according to the Newcastle-Ottawa Scale (http://www.ohri. ca/programs/clinical_epidemiology/oxford.asp).

\section{Statistical analysis}

This meta-analysis was carried out using the Stata version 11. All $P$ values were two-sided and a $P$ value of less than 0.05 was deemed statistically significant. In the included studies, if continuous data described as medians and ranges, these data were analyzed by approach reported by Hozo et al. [26] to calculate mean and standard deviations (SD). Sometimes it is desirable to combine two reported subgroups into a single group, we use the formulae for combining groups according to Cochrane Handbook for Systematic Reviews of Interventions (2008) [27]. Continuous variables used weighted mean difference (WMD) and a 95\% confidence interval (CI). The relative risk (RR) with a 95\% confidence interval (CI) was calculated for dichotomous outcomes (fetal loss and preterm delivery). If one cell in the $2 \times 2$ table contained zero, a continuity correction was carried by adding 0.5 to each cell $[28,29]$. A fixed effect mode or a random effects model mode was applied. Heterogeneity was evaluated by $x^{2}$-test and $I^{2}$. We considered heterogeneity to be present if the $I^{2}$ statistic was $>50 \%$, and a random effect model were adopted. However, if $I^{2}$ statistic was $<50 \%$, we used a fixed effect model. $P<0.05$ was considered to be significant. Funnel plot was used to evaluate publication of bias. In addition, funnel plot asymmetry was assessed by the method of Egger's linear regression test [30]. 


\section{Results}

Finally, nine retrospective trials with a total of 985 patients were included into this meta-analysis $[8,15,17,22,24$, 31-34]. In the 985 patients, 549 had undergone laparoscopic surgery and 436 had undergone open surgery. All studies included were published in English. The baseline characteristics and quality assessment of all included studies are listed in Table 1. All the included studies mentioned the mean age, and seven studies described gestational age at surgery. In this meta-analysis, we found that there was no statistical difference in age and gestational age between two groups. The mean patient age ranged from 27.0 to 31.5 years. Gestational age at diagnosis was mostly in the second trimester. Fetal loss and preterm labor were reported in all nine studies. Eight studies reported on operation time and seven reported hospital stay, and four reported blood loss.
22 potentially relevant articles identified following search criteria and screened for retrieval

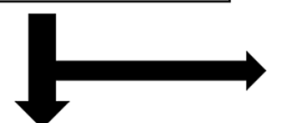

8 articles excluded ( eg: noncomparison studies, reviews et al.)

14 full- text articles assessed for eligibility

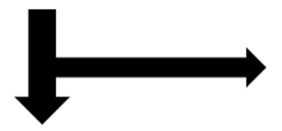

5 articles excluded (having no available data)

9 retrospective controlled trials included into meta-analysis

Fig. 1 Flow chart demonstrating selection of studies for inclusion in the meta-analysis

Table 1 The baseline characteristics and quality assessment of studies

\begin{tabular}{|c|c|c|c|c|c|c|}
\hline References & Quality score & Design & $\begin{array}{l}\text { No. of women } \\
\text { LA versus OP }\end{array}$ & Age (years) LA versus OP & $\begin{array}{l}\text { Gestational (weeks) LA } \\
\text { versus OP }\end{array}$ & Outcomes \\
\hline Ngu [8] & $8^{\mathrm{a}}$ & $\mathrm{R}$ & 21 versus 14 & $31.4 \pm 4.3$ versus $31.6 \pm 7.0$ & $15.1 \pm 1.8$ versus $15.4 \pm 2.2$ & $\begin{array}{l}\text { Fetal loss, preterm delivery, } \\
\text { hospital stay, duration of } \\
\text { operation, birth weight, } \\
\text { lost blood. mass size }\end{array}$ \\
\hline Koo [17] & $8^{\mathrm{a}}$ & $\mathrm{R}$ & 88 versus 174 & $30.1 \pm 3.6$ versus $29.4 \pm 3.3$ & $11.6 \pm 3.1$ versus $15.1 \pm 4.5$ & $\begin{array}{l}\text { Apgar score, fetal loss, } \\
\text { preterm delivery, hospital } \\
\text { stay, duration of operation } \\
\text { mass size, birth weight }\end{array}$ \\
\hline Chang [34] & $8^{\mathrm{a}}$ & $\mathrm{R}$ & 12 versus 8 & $29.1 \pm 4.8$ versus $29.8 \pm 5.8$ & NA & $\begin{array}{l}\text { Fetal loss, preterm delivery, } \\
\text { hospital stay, duration of } \\
\text { operation, lost blood }\end{array}$ \\
\hline Balthazar [15] & $9^{a}$ & $\mathrm{R}$ & 50 versus 51 & $27.6 \pm 5.5$ versus $25.4 \pm 5.7$ & $17.6 \pm 0.4$ versus $17.5 \pm 0.5$ & $\begin{array}{l}\text { Preterm delivery, hospital } \\
\text { stay, duration of operation } \\
\text { blood lost, birth weight }\end{array}$ \\
\hline Lee [22] & $6^{\mathrm{a}}$ & $\mathrm{R}$ & 17 versus 17 & $30.0 \pm 3.5$ versus $28.5 \pm 3.0$ & $12.9 \pm 2.2$ versus $12.4 \pm 3.5$ & $\begin{array}{l}\text { Apgar score, fetal loss, } \\
\text { preterm delivery, hospital } \\
\text { stay, duration of operation } \\
\text { lost blood }\end{array}$ \\
\hline James [33] & $6^{\mathrm{a}}$ & $\mathrm{R}$ & 7 versus 9 & $27.1 \pm 3.7$ versus $22.9 \pm 5.3$ & $15.0 \pm 6.0$ versus $13.0 \pm 4.0$ & $\begin{array}{l}\text { Fetal loss, preterm delivery, } \\
\text { duration of operation, } \\
\text { hospital stay }\end{array}$ \\
\hline Oelsner [32] & $7^{\mathrm{a}}$ & $\mathrm{R}$ & 192 versus 197 & $28.9 \pm 6.0 \mathrm{VS} 28.3 \pm 5.5$ & NA & $\begin{array}{l}\text { Fetal loss, duration of } \\
\text { operation, hospital stay, } \\
\text { birthweight }\end{array}$ \\
\hline Akira [31] & $8^{\mathrm{a}}$ & $\mathrm{R}$ & 17 versus 18 & $30.6 \pm 4.9$ versus $29.7 \pm 5.1$ & $13.9 \pm 1.4$ versus $14.1 \pm 2.1$ & $\begin{array}{l}\text { Fetal loss, preterm delivery, } \\
\text { duration of operation }\end{array}$ \\
\hline Soriano [24] & $7^{\mathrm{a}}$ & $\mathrm{R}$ & 39 versus 54 & $28.3 \pm 3.4$ versus $27.0 \pm 2.9$ & $8.3 \pm 1.7$ versus $14.7 \pm 5.9$ & $\begin{array}{l}\text { Fetal loss, preterm delivery, } \\
\text { birth weight }\end{array}$ \\
\hline
\end{tabular}

NA not available

${ }^{\text {a }}$ Values are expressed as mean $\pm \mathrm{SD}$ 


\section{Fetal loss}

As shown in Fig. 1, the search strategy identified nine controlled trials that compared the results of laparoscopy to open surgery for adnexal mass during pregnancy. All nine studies reported fetal loss after surgery, which allowed quantitative pooled analysis. The RRs were homogeneous across studies $Q=3.93, P=0.863, I^{2}=0.0 \%<50 \%$ with a pooled value (laparoscopy versus open surgery) of 1.36 the results of the meta-analysis for fetal loss are shown in Table 2 and Fig. 2. This suggested that the odds of fetal loss in the laparoscopy were almost as same as the open surgery. Egger's test suggested asymmetry of the funnel $(t=-3.60$, $P=0.009$ ). A contour-enhanced funnel plot was, therefore, created (Fig. 3). The funnel plot revealed an apparent asymmetry that prompted the presence of a potential publication bias, a language bias, inflated estimates by a flawed methodologic design in smaller studies, and/or a lack of publication of small trials with opposite results. (95\% CI $0.73-2.55, P=0.334$ ). Forest plots displaying

\section{Preterm labor}

All nine studies reported preterm labor. The RRs were homogeneous $Q=9.69, P=0.288, I^{2}=17.4 \%<50 \%$. The pooled RR was 0.510 (95\% CI $0.299-0.871, P=0.014$ ). (Table 2, Fig. 4), indicating that the odds of preterm labor was $51 \%$ lower in the laparoscopy than the open surgery group $(P=0.01)$; Egger's test did not suggest publication bias $(t=0.37, P=0.721)$ and this was supported by a symmetrical contour-enhanced funnel plot (Fig. 5).

\section{Operation time}

Duration of operation was also pooled across studies (Table 3). The duration of operation in the laparoscopy and open groups was compared in eight studies $(n=892)$. The data were heterogeneous $Q=91.47, P<0.001$, $I^{2}=92.3 \%>50 \%$, with an unstandardized mean difference of 5.42 ( -5.85 to 16.68$)$, indicating that the duration of operation was not significant between LA group and OP group $(P=0.346)$ (Fig. 6). Egger's test did not suggest publication bias $(P=0.249)$.

\section{Blood loss}

Table 2 Comparisons of fetal loss and preterm labor between laparoscopic and open surgery in pregnancy

\begin{tabular}{lrrrrrl}
\hline References & \multicolumn{2}{l}{$\begin{array}{l}\text { Laparo- } \\
\text { scopic }\end{array}$} & & Open & & Relative risk \\
\cline { 2 - 3 } \cline { 6 - 7 } & Yes & No & & Yes & No & \\
\hline Fetal loss & & & & & \\
Ngu [8] & 0 & 20 & 1 & 12 & $0.22(0.01-5.08)$ \\
Koo [17] & 2 & 86 & 3 & 171 & $1.32(0.22,7.75)$ \\
Chang [34] & 3 & 9 & 2 & 6 & $1.00(0.21,4.71)$ \\
Balthazar [15] & 0 & 50 & 0 & 51 & $1.02(0.02,50.41)$ \\
Lee [22] & 0 & 17 & 0 & 17 & $1.00(0.02,47.63)$ \\
James [33] & 0 & 7 & 1 & 8 & $0.42(0.02,8.91)$ \\
Oelsner [32] & 15 & 177 & 7 & 190 & $2.20(0.92,5.27)$ \\
Akira [31] & 0 & 17 & 1 & 17 & $0.35(0.02,8.09)$ \\
Soriano [24] & 0 & 39 & 0 & 54 & $1.38(0.03,68.06)$ \\
Pooled relative risk & & & & & $1.36(0.73,2.55)$ \\
Preterm delivery & & & & & \\
Ngu [8] & 2 & 18 & 1 & 12 & $1.30(0.13-12.92)$ \\
Koo [17] & 2 & 86 & 33 & 141 & $0.12(0.03,0.49)$ \\
Chang [34] & 2 & 10 & 1 & 7 & $1.33(0.14,12.37)$ \\
Balthazar [15] & 3 & 47 & 3 & 48 & $1.02(0.22,4.82)$ \\
Lee [22] & 1 & 16 & 1 & 16 & $1.00(0.07,14.72)$ \\
James [33] & 1 & 6 & 3 & 4 & $0.33(0.05,2.48)$ \\
Oelsner [32] & 5 & 187 & 6 & 191 & $0.86(0.27,2.76)$ \\
Akira [31] & 0 & 17 & 0 & 18 & $1.06(0.02,50.43)$ \\
Soriano [24] & 4 & 35 & 4 & 50 & $1.39(0.37,5.20)$ \\
Pooled relative risk & & & & & $0.51(0.30,0.87)$ \\
\hline & & & & &
\end{tabular}

Among four studies reported on blood loss during operation, one was discarded for no datum, three were meta-analyzed. It was found to be significantly lower in the laparoscopy group versus the open group by $83.81 \mathrm{ml}$ (95\% CI $-121.54 \sim-13.26, P=0.015$ ) (Fig. 7) with significant heterogeneity $Q=91.47, P<0.001, I^{2}=92.3 \%>50 \%$. Egger's test did not suggest publication bias $(P=0.606)$.

\section{Hospital stay}

There were six studies that reported hospital stay while one was excluded for being unable to obtain valid SD. The length of hospital stay was significantly shorter in the laparoscopy group by almost 2 days (95\% CI -2.34 to 1.55 , $P<0.001$ ) (Fig. 8). Egger's test did not suggest publication bias $(P=0.682)$.

\section{Discussion}

Our systematic reviews and meta-analysis investigated all controlled clinical trials according to the inclusion criteria. The search strategy employed in the present meta-analysis was broad. Those derived from searching proceedings databases were not specifically excluded. According to the quality evaluation of Newcastle-Ottawa Scale results (NOS) for meta-analysis of non-randomized studies, the quality of most of the studies was considered to be high. The results 


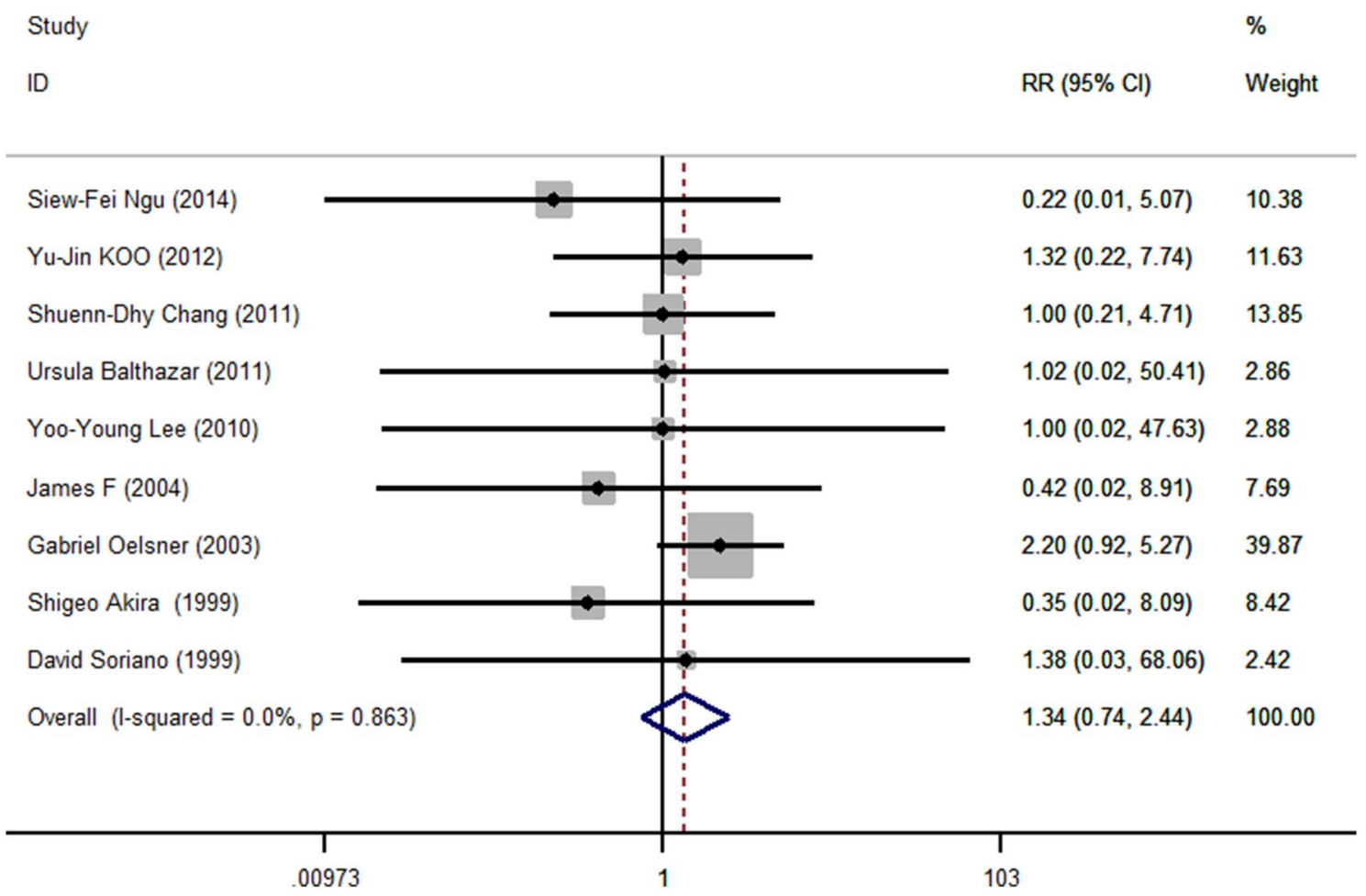

Fig. 2 Meta-analysis of pregnancy outcomes fetal loss after laparoscopic (LA) versus open (OA) surgery. Relative risks are shown with 95\% confidence intervals

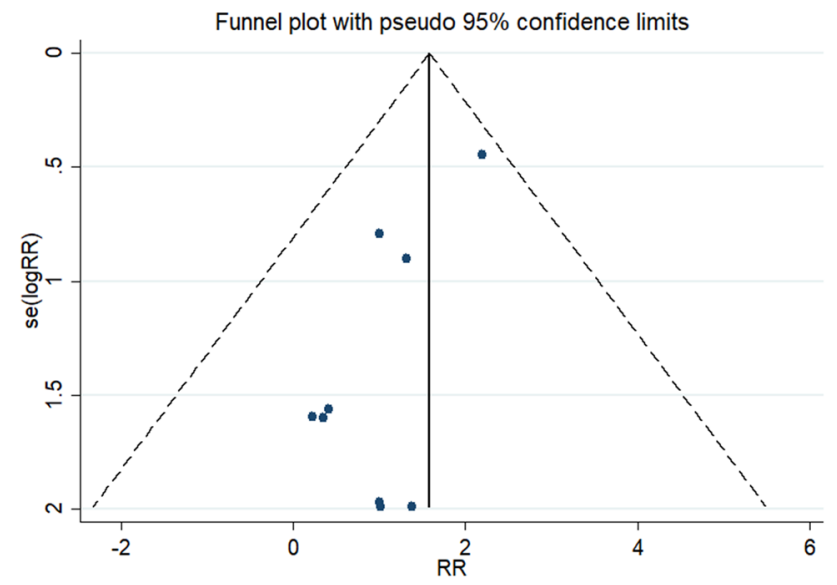

Fig. 3 Contour-enhanced funnel plots for studies comparing fetal loss after laparoscopic versus open surgery

of this meta-analysis suggest that laparoscopic surgery in pregnancy results in almost $51 \%$ lower risk of preterm labor, shorter hospital stay and lower blood loss compared with open surgery. No significant difference in fetal loss and operation time was observed between the two groups.

To date, a considerable number of studies demonstrate that laparoscopic surgery during pregnancy has been performed successfully for many conditions, such as cholecystectomy and appendectomy [18, 19, 35, 36], which have an advantage of good maternal outcomes, such as earlier ambulation, less pain after surgery and shorter hospital stay than open surgery [37]. At the same time, previous controlled studies have shown that it is not associated with higher rates of abortion and preterm deliveries in comparison with laparotomy $[33,34]$. A meta-analysis has been published to review the effects of laparoscopic and open appendectomy in pregnancy [29]. However, previous randomized studies of laparoscopy versus open surgery in pregnant patients with adnexal mass are limited.

The risk of fetal loss has become the top priority in many studies of the relative safety of laparoscopy in pregnancy $[38,39]$. The main consideration is laparoscopy requires carbon dioxide pneumoperitoneum [40]. Increased intraabdominal pressure can lead to reduced uterine blood flow and maternal venous return, resulting in the fetal intrauterine hypoxia [41, 42]. Another factor associated with pneumoperitoneum is that carbon dioxide can be absorbed across the peritoneum, causing fetal acidosis [43]. However, Curet MJ hold no substantial adverse effect on the fetus when the maximum pressure of the pneumoperitoneal is less than $12 \mathrm{mmHg}$ and the duration is less than $30 \mathrm{~min}$ [40]. To avoid this risk, the gasless laparoscopic technique was, therefore, recommended for pregnancy surgery $[20,31,44$, 45]. Another concern for the application of laparoscopic 


\section{Study}

ID
$\%$

$\operatorname{RR}(95 \% \mathrm{Cl})$
Weight

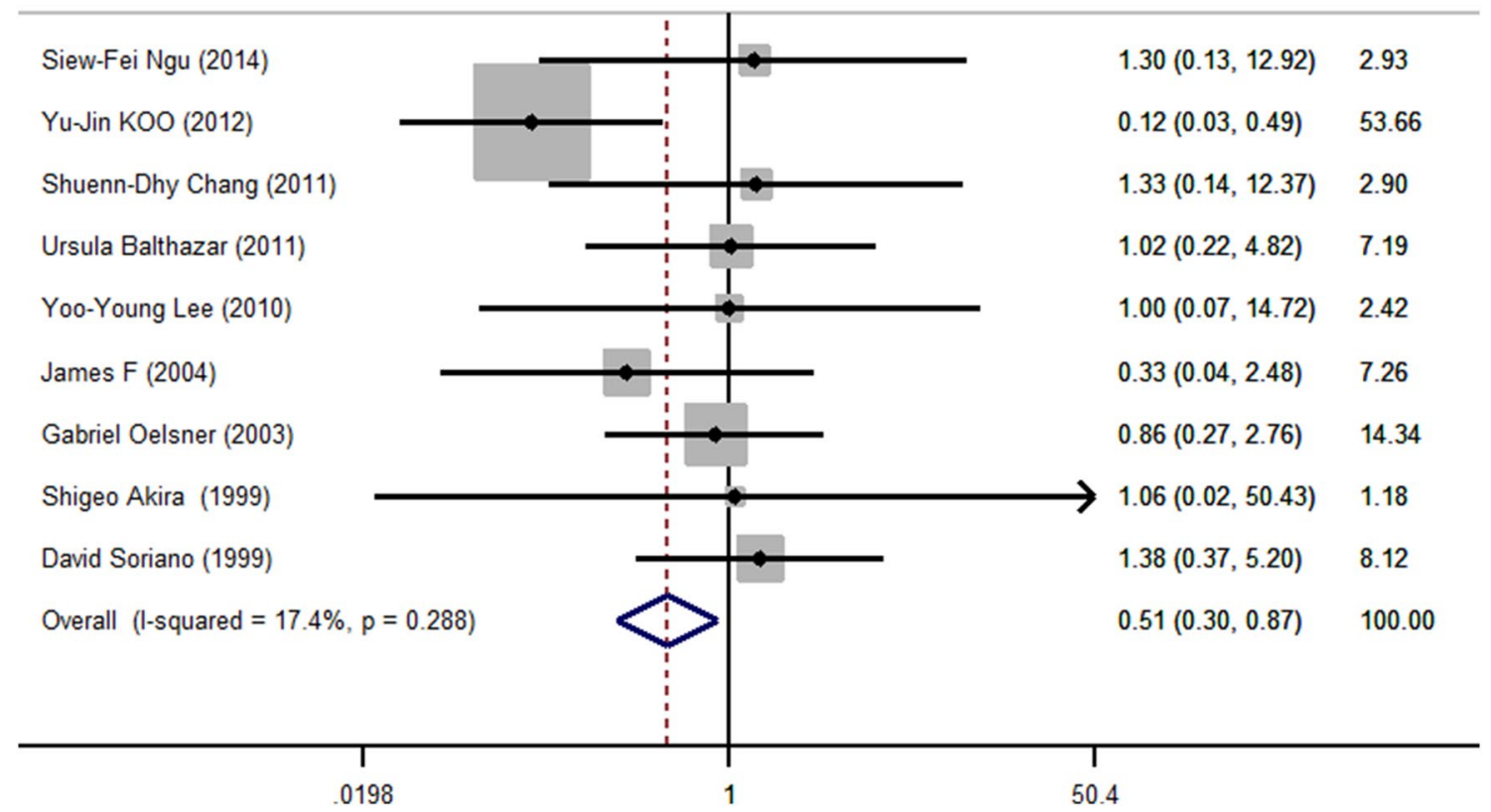

Fig. 4 Meta-analysis of pregnancy outcomes preterm labor after laparoscopic (LA) versus open (OA) surgery. Relative risks are shown with 95\% confidence intervals

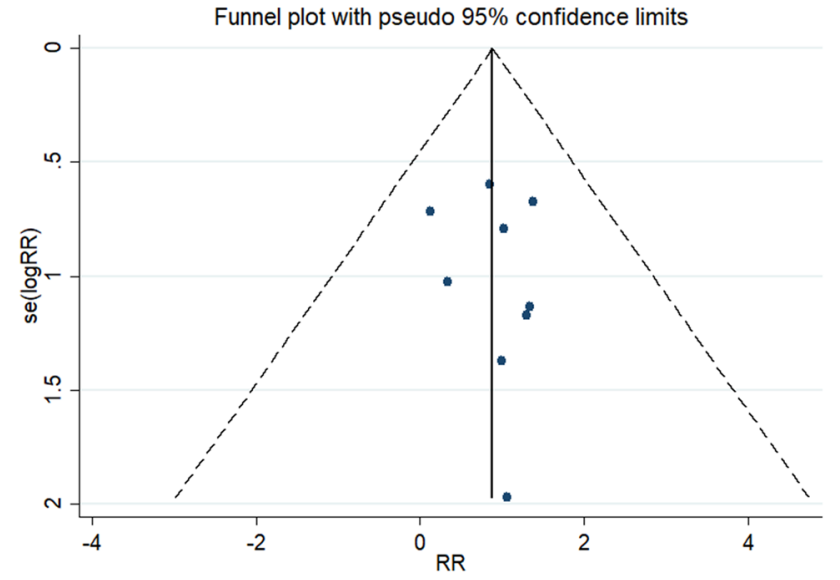

Fig. 5 Contour-enhanced funnel plots for studies comparing preterm labor after laparoscopic versus open surgery

surgery during pregnancy is the risk of injury to the enlarged uterus [46, 47]. In the study of Balthazar [15], initial port was placed through an open method $(80 \%)$ or a left upper quadrant entry (11\%), thereby reducing the potential risk of penetrating injury to the gravid uterus. In all, although there is no statistical significance, the present results suggest that the risk of fetal loss may be increased in those undergoing laparoscopic surgery compared with open surgery. It is likely that this analysis did not have enough statistical capabilities to detect a significant difference, because a sample size of 985 would be required in each group to detect a RR of 1.36.

The risk of preterm labor after laparoscopy compared with open surgery has been discussed in many reports of the relative safety of laparoscopy in pregnancy [32, 48, 49]. The relative risk (RR) of the preterm labor between laparoscopy versus open surgery in this study was estimated as carried out by Wilasrusmee et al. [29], because the number of fetal loss is not excluded in data processing; it is difficult to reach a conclusion that laparoscopy has an advantage in preterm labor though the result indicates that the odds of preterm labor was $51 \%$ lower in the laparoscopy than the open surgery group $(P=0.014)$. In this study the increase of operating time in laparoscopic surgery is not statistically significant, probably due to the influence of the learning curve. Meanwhile, similar to the findings in non-gravid patients, laparoscopy was associated with improved shortterm operative outcomes including decreased blood loss and shorter hospital stay. The results showed that the amount of blood loss $(83.81 \mathrm{ml}, P=0.00)$ in the laparoscopy group was significantly reduced, which may attribute to the better visualization of deep vascular structures, and possibly more precise and accurate surgery. The length of hospital stay was approximately 2 days shorter in laparoscopy than that of open surgery $(P<0.000)$. However, these results should 
Table 3 Comparisons of duration of operation, blood loss and hospital stay between laparoscopic and open surgery in pregnancy

\begin{tabular}{|c|c|c|c|c|c|c|c|c|}
\hline \multirow[t]{2}{*}{ References } & \multicolumn{2}{|c|}{ Operation time $(\mathrm{min})$} & \multicolumn{2}{|c|}{ Blood lost (ml) } & \multicolumn{2}{|l|}{ Birth weight $(\mathrm{g})$} & \multicolumn{2}{|c|}{ Hospital stay (days) } \\
\hline & LA & OP & LA & OP & LA & OP & LA & OP \\
\hline Ngu [8] & $92.5 \pm 44.4$ & $67.6 \pm 29.3$ & $67.4 \pm 55.8$ & $153.6 \pm 181.0$ & $3188.8 \pm 343.5$ & $3163.6 \pm 445.6$ & $2.8 \pm 1.0$ & $3.8 \pm 1.1$ \\
\hline Koo [17] & $60.7 \pm 27.1$ & $69.7 \pm 24.4$ & NA & NA & $3174.7 \pm 539.8$ & $3197.2 \pm 554.2$ & $4.7 \pm 1.7$ & $6.6 \pm 1.3$ \\
\hline Chang [34] & $87.9 \pm 39.9$ & $94.8 \pm 44.6$ & $58.8 \pm 32.1$ & $53.8 \pm 60.9$ & NA & NA & $2.9 \pm 1.1$ & $7.6 \pm 7.9$ \\
\hline Balthazar [15] & $76.6 \pm 3.1$ & $62.8 \pm 2.7$ & $17.5 \pm 1.6$ & $101.5 \pm 8.3$ & NA & NA & $0.7 \pm 0.1$ & $2.8 \pm 0.2$ \\
\hline Lee [22] & $106.3 \pm 31.3$ & $117.8 \pm 49.8$ & $152.5 \pm 97.5$ & $275.0 \pm 125.0$ & NA & NA & $3.5 \pm 1.0$ & $6.5 \pm 1.0$ \\
\hline James [33] & $116 \pm 34$ & $89 \pm 35$ & Minimal & $117 \pm 75$ & NA & NA & $1.0 \pm 0.0$ & $4.4 \pm 1.1$ \\
\hline Oelsner [32] & \pm 25 & $64 \pm 28.6$ & NA & NA & NA & NA & $2.7 \pm 2.1$ & $4.3 \pm 2.0$ \\
\hline Akira [31] & $75.4 \pm 18.5$ & $58.2 \pm 25.5$ & NA & NA & NA & NA & NA & NA \\
\hline Soriano [24] & NA & NA & NA & NA & NA & NA & NA & NA \\
\hline
\end{tabular}

Values are expressed as mean \pm SD

$N A$ not available

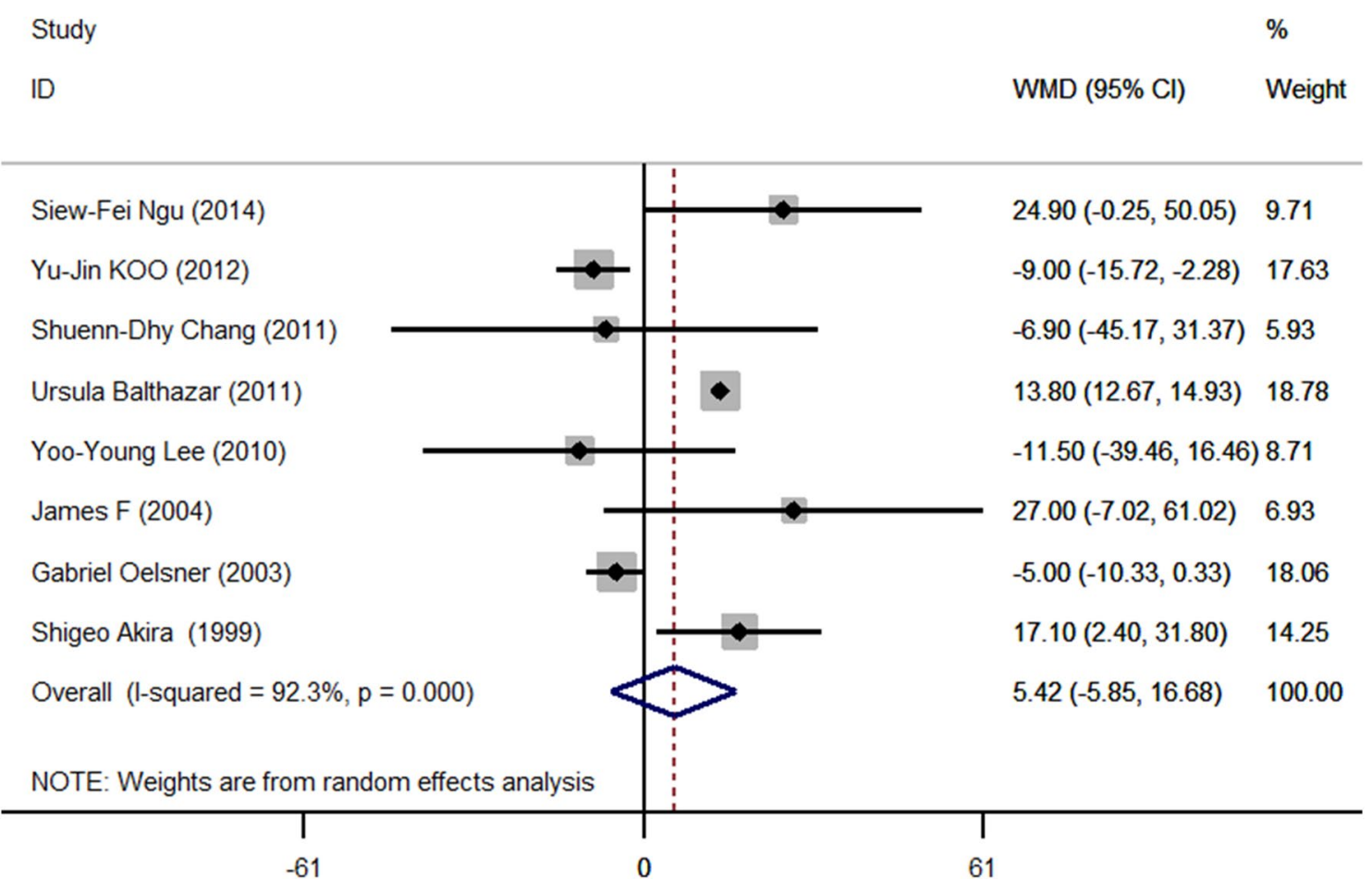

Fig. 6 Meta-analysis of operation time in laparoscopic (LA) versus open (OA) surgery. Relative risks are shown with 95\% confidence intervals

be interpreted with caution as the total number of patients is small and significant heterogeneity.

Meta-analytical research has several limitations that must be taken into account when its results are considered. One major potential limitation here is that all studies included in the review were observational, and summary data published within each study were included in the analysis. While not all cases in the studies were adnexal mass, some were found to be appendicitis or cholecystitis during surgery, or considered to be malignant by pathologic results, and these, therefore, limited the comparability of the results. Besides, many other factors (such as patient age, gravidity, duration of pregnancy, weight gain, tocolytic treatment, mass size, the percentage of emergency operations undertaken, variation in the surgical procedures and the surgeon's experience) may affect the clinical heterogeneity. Confounding bias cannot be ignored as the included studies were retrospective. There were no available data on pregnancy complications, nor was it possible to assess whether the effects of laparoscopic surgery on pregnancy outcomes were associated with other 
Study

ID
$\%$

WMD $(95 \% \mathrm{Cl})$

Weight

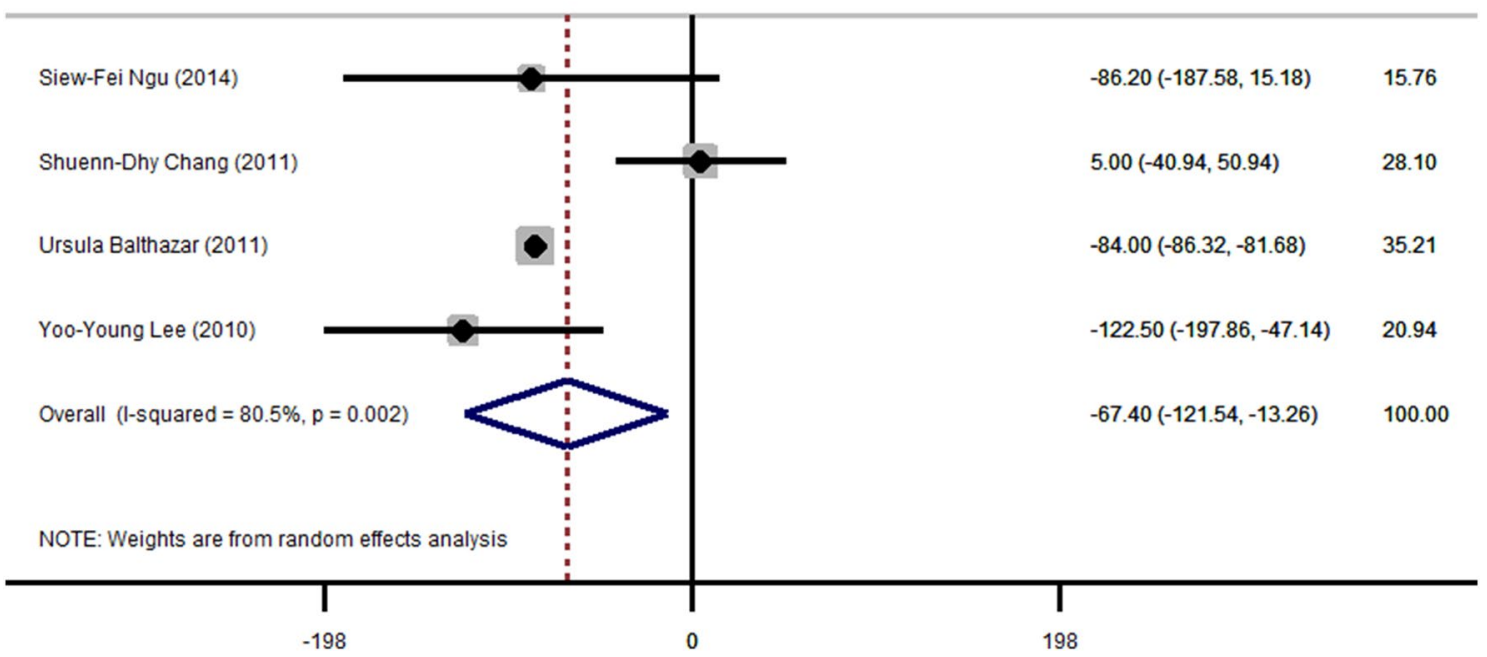

Fig. 7 Meta-analysis of blood loss in laparoscopic (LA) versus open (OA) surgery. Relative risks are shown with 95\% confidence intervals

$$
\text { Study }
$$

ID
$\%$

WMD $(95 \% \mathrm{Cl}) \quad$ Weight

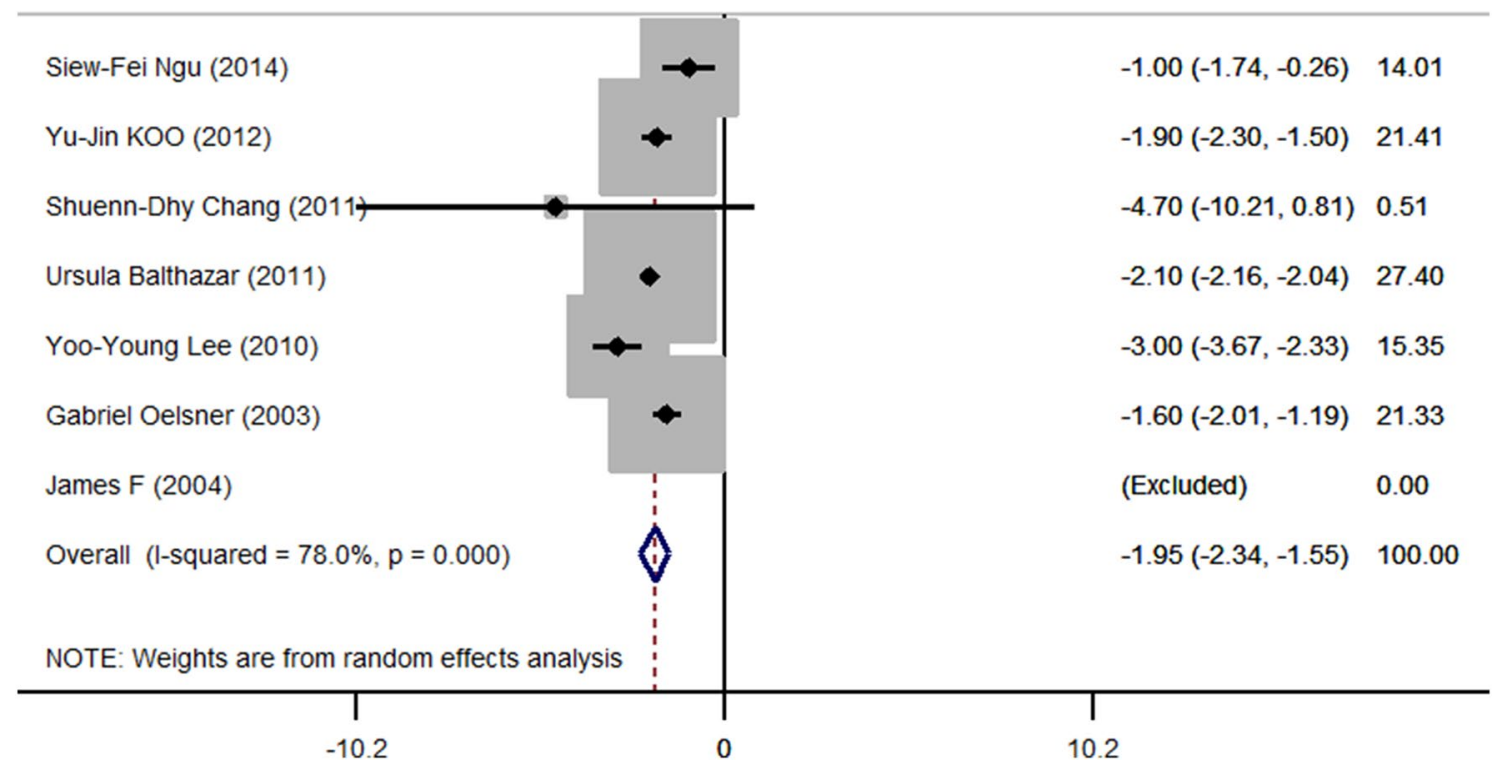

Fig. 8 Meta-analysis of hospital stay in laparoscopic (LA) versus open (OA) surgery. Relative risks are shown with 95\% confidence intervals

pregnancy complications. Therefore, further large-scale randomized trials are needed to confirm the present findings. However, it may be difficult to perform a randomized trial due to the particularity of pregnant women. In addition, the statistically significant difference in fetal outcomes was not possible to be identified owing to the limited number of studies available for pooling. Neither the allocation of surgical methods nor the assessment of outcome was blind, and it is important to bear in mind publication bias, particularly in meta-analytical research based on published studies. 


\section{Conclusions}

This study presented that laparoscopic surgery for pregnant women with adnexal mass was associated with less operative blood loss, reduced time in hospital and decreased rate of preterm labor. What is more, no significance was found in terms of fetal loss. More results should be awaited with particular interest on the outcomes mentioned above, given that only a few controlled trials published that limit exploration of the results to the clinical setting.

Author contributions PY: protocol/project development and manuscript editing; NZ: project development and data collection; JS: data collection; HS: data collection and data analysis; YW: data collection and data analysis; LC: data management and manuscript writing; XY: protocol development, manuscript writing and editing.

Funding This work was supported by fund from the National Natural Science Foundation of China No. 81503293 (X. J. Y.).

\section{Compliance with ethical standards}

Conflict of interest The authors declare that they have no conflict of interest.

Ethical approval This article does not contain any studies with human participants or animals performed by any of the authors.

OpenAccess This article is distributed under the terms of the Creative Commons Attribution 4.0 International License (http://creativeco mmons.org/licenses/by/4.0/), which permits unrestricted use, distribution, and reproduction in any medium, provided you give appropriate credit to the original author(s) and the source, provide a link to the Creative Commons license, and indicate if changes were made.

\section{References}

1. Palmer J, Vatish M, Tidy J (2009) Epithelial ovarian cancer in pregnancy: a review of the literature. BJOG 116:480-491

2. Hess LW, Peaceman A, O'Brien WF, Winkel CA, Cruikshank DP, Morrison JC (1988) Adnexal mass occurring with intrauterine pregnancy: report of fifty-four patients requiring laparotomy for definitive management. Am J Obstet Gynecol 158:1029-1034

3. Jacob JH, Stringer CA (1990) Diagnosis and management of cancer during pregnancy. Semin Perinatol 14:79-87

4. Webb KE, Sakhel K, Chauhan SP, Abuhamad AZ (2015) Adnexal mass during pregnancy: a review. Am J Perinatol 32:1010-1016

5. Kim M (2016) Laparoscopic management of a twisted ovarian leiomyoma in a woman with 10 weeks' gestation: case report and literature review. Medicine (Baltimore) 95:e5319

6. Chung A, Birnbaum SJ (1973) Ovarian cancer associated with pregnancy. Obstet Gynecol 41:211-214

7. Brodsky JB, Cohen EN, Brown BW Jr et al (1980) Surgery during pregnancy and fetal outcome. Am J Obstet Gynecol 138:1165-1167

8. Ngu Siew-Fei, Cheung Vincent, Pun Ting-Chung (2014) Surgical management of adnexal masses in pregnancy. JSLS 18:71-75
9. Amos JD, Schorr SJ, Norman PF, Poole GV, Thomae KR, Mancino AT et al (1996) Laparoscopic surgery during pregnancy. Am J Surg 171:435-437

10. Roberts JA (1983) Management of gynecologic tumors during pregnancy. Clin Perinatol 10:369-382

11. Sherard GB 3rd, Hodson CA, Williams HJ, Semer DA, Hadi HA, Tait DL (2003) Adnexal masses and pregnancy: a 12-year experience. Am J Obstet Gynecol 189:358-362

12. Laparoscopic surgery for presumed benign ovarian tumor during pregnancy (Review) 3 Copyright $@ 2009$ The Cochrane Collaboration. Wiley, Hoboken

13. Ribic-Pucelj M, Kobal B, Peternelj-Marinsek S (2007) Surgical treatment of adnexal masses in pregnancy: indications, surgical approach and pregnancy outcome. J Reprod Med 52:273-279

14. Yuen PM, Ng PS, Leung PL, Rogers MS (2004) Outcome in laparoscopic management of persistent adnexal mass during the second trimester of pregnancy. Surg Endosc 18:1354-1357

15. Balthazar U, Steiner AZ, Boggess JF, Gehrig PA (2011) Management of a persistent adnexal mass in pregnancy: what is the ideal surgical approach? J Minim Invasive Gynecol 18:720-725

16. Mathevet P, Nessah K, Dargent D, Mellier G (2003) Laparoscopic management of adnexal masses in pregnancy: a case series. Eur J Obstet Gynecol Reprod Biol 108:217-222

17. Koo YJ, Kim HJ, Lim KT, Lee IH, Lee KH, Shim JU et al (2012) Laparotomy versus laparoscopy for the treatment of adnexal masses during pregnancy. Aust N Z J Obstet Gynaecol 52:34-38

18. Corneille MG, Gallup TM, Bening T, Wolf SE, Brougher C, Myers JG et al (2010) The use of laparoscopic surgery in pregnancy: evaluation of safety and efficacy. Am J Surg 200:363-367

19. Palanivelu $C$, Rangarajan M, Senthilkumaran S, Parthasarathi $R$ (2007) Safety and efficacy of laparoscopic surgery in pregnancy: experience of a single institution. J Laparoendosc Adv Surg Tech A 17:186-190

20. Phupong V, Bunyavejchewin S (2007) Gasless laparoscopic surgery for ovarian cyst in a second trimester pregnant patient with a ventricular septal defect. Surg Laparosc Endosc Percutan Tech 17:565-567

21. Oguri H, Taniguchi K, Fukaya T (2005) Gasless laparoscopic management of ovarian cysts during pregnancy. Int J Gynaecol Obstet 91:258-259

22. Lee YY, Kim TJ, Choi CH, Lee JW, Kim BG, Bae DS (2010) Factors influencing the choice of laparoscopy or laparotomy in pregnant women with presumptive benign ovarian tumors. Int $\mathbf{J}$ Gynaecol Obstet 108:12-15

23. Patacchiola F, Collevecchio N, Di Ferdinando A, Palermo P, Di Stefano L, Mascaretti G (2005) Management of ovarian cysts in pregnancy: a case report. Eur J Gynaecol Oncol 26:651-653

24. Soriano D, Yefet Y, Seidman DS, Goldenberg M, Mashiach S, Oelsner G (1999) Laparoscopy versus laparotomy in the management of adnexal masses during pregnancy. Fertil Steril 71:955-960

25. Zacharoula S, Setubal A (2014) Acute abdomen in pregnancy due to isolated fallopian tube torsion: the laparoscopic treatment of a rare case. World J Clin Cases 2:724-727

26. Hozo SP, Djulbegovic B, Hozo I (2005) Estimating the mean and variance from the median, range, and the size of a sample. BMC Med Res Methodol 5:13

27. Higgins JPT, Deeks JJ (2008) Chapter 7: Selecting studies and collecting data. In: Higgins JPT, Green S (eds) Cochrane handbook for systematic reviews of interventions. Wiley, Chichester

28. Fleiss JL (1993) The statistical basis of meta-analysis. Stat Methods Med Res 2:121-145

29. Wilasrusmee C, Sukrat B, McEvoy M, Attia J, Thakkinstian A (2012) Systematic review and meta-analysis of safety of laparoscopic versus open appendicectomy for suspected appendicitis in pregnancy. Br J Surg 99:1470-1478 
30. Egger M, Davey Smith G, Schneider M, Minder C (1997) Bias in meta-analysis detected by a simple, graphical test. BMJ 315:629-634

31. Akira S, Yamanaka A, Ishihara T, Takeshita T, Araki T (1999) Gasless laparoscopic ovarian cystectomy during pregnancy: comparison with laparotomy. Am J Obstet Gynecol 180:554-557

32. Oelsner G, Stockheim D, Soriano D, Goldenberg M, Seidman DS, Cohen SB et al (2003) Pregnancy outcome after laparoscopy or laparotomy in pregnancy. J Am Assoc Gynecol Laparosc 10:200-204

33. Carter JF, Soper DE (2004) Operative laparoscopy in pregnancy. JSLS 8:57-60

34. Chang SD, Yen CF, Lo LM, Lee CL, Liang CC (2011) Surgical intervention for maternal ovarian torsion in pregnancy. Taiwan $\mathrm{J}$ Obstet Gynecol 4:458-462

35. Park SH, Park MI, Choi JS, Lee JH, Kim HO, Kim H (2010) Laparoscopic appendectomy performed during pregnancy by gynecological laparoscopists. Eur J Obstet Gynecol Reprod Biol 148:44-48

36. Lemieux P, Rheaume P, Levesque I, Bujold E, Brochu G (2009) Laparoscopic appendectomy in pregnant patients: a review of 45 cases. Surg Endosc 23:1701-1705

37. Al-Fozan H, Tulandi T (2002) Safety and risks of laparoscopy in pregnancy. Curr Opin Obstet Gynecol 14:375-379

38. Lin YH, Hwang JL, Huang LW, Seow KM (2003) Successful laparoscopic management of a huge ovarian tumor in the 27 th week of pregnancy. A case report. J Reprod Med 48:834-836

39. Yamada H, Ohki H, Fujimoto K, Okutsu Y (2004) Laparoscopic ovarian cystectomy with abdominal wall lift during pregnancy under combined spinal-epidural anesthesia. Masui 53:1155-1158

40. Curet MJ, Vogt DA, Schob O, Qualls C, Izquierdo LA, Zucker $\mathrm{KA}$ (1996) Effects of $\mathrm{CO}_{2}$ pneumoperitoneum in pregnant ewes. J Surg Res 63:339-344
41. Westerband A, Van De Water A, Amzallag M, Lebowitz PW, Nwasokwa ON, Chardavoyne R et al (1992) Cardiovascular changes during laparoscopic cholecystectomy. Surg Gynecol Obstet 175:535-538

42. Kammerer WS (1979) Nonobstetric surgery during pregnancy. Med Clin North Am 63:1157-1164

43. Soper NJ, Hunter JG, Petrie RH (1992) Laparoscopic cholecystectomy during pregnancy. Surg Endosc 6:115-117

44. Takeda A, Hayashi S, Imoto S, Sugiyama C, Nakamura H (2014) Pregnancy outcomes after emergent laparoscopic surgery for acute adnexal disorders at less than 10 weeks of gestation. J Obstet Gynaecol Res 40:1281-1287

45. Sesti F, Pietropolli A, Sesti FF, Piccione E (2013) Gasless laparoscopic surgery during pregnancy: evaluation of its role and usefulness. Eur J Obstet Gynecol Reprod Biol 170:8-12

46. Friedman JD, Ramsey PS, Ramin KD, Berry C (2002) Pneumoamnion and pregnancy loss after second-trimester laparoscopic surgery. Obstet Gynecol 99:512-513

47. Moreno-Sanz C, Pascual-Pedreno A, Picazo-Yeste JS, SeoaneGonzalez JB (2007) Laparoscopic appendectomy during pregnancy: between personal experiences and scientific evidence. J Am Coll Surg 205:37-42

48. Chohan L, Kilpatrick CC (2009) Laparoscopy in pregnancy: a literature review. Clin Obstet Gynecol 52:557-569

49. Nezhat FR, Tazuke S, Nezhat CH, Seidman DS, Phillips DR, Nezhat CR (1997) Laparoscopy during pregnancy: a literature review. JSLS 1:7-27

Publisher's Note Springer Nature remains neutral with regard to jurisdictional claims in published maps and institutional affiliations. 